\title{
Epidemiological Aspects of Cerebrovascular Accidents in the Diabetic: Experience of the Medical Clinic II of the Hospital Center Abass Ndao of Dakar
}

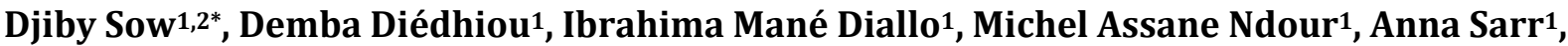 \\ Maimouna Ndour-Mbaye1, Norou Diop Saïd1 \\ ${ }^{1}$ Department of Internal Medicine II, University Hospital Center of Dakar, Cheikh Anta Diop University, Dakar, Senegal \\ ${ }^{2}$ Department of Internal Medicine, Abass Ndao Hospital Center, Cheikh Anta Diop University, Dakar, Sénéga \\ Email: *drdjiby@yahoo.fr
}

How to cite this paper: Sow, D., Diédhiou, D., Diallo, I.M., Ndour, M.A., Sarr, A., Ndour-Mbaye, M. and Saï, N.D. (2018) Epidemiological Aspects of Cerebrovascular Accidents in the Diabetic: Experience of the Medical Clinic II of the Hospital Center Abass Ndao of Dakar. Open Journal of Endocrine and Metabolic Diseases, 8, 9-18. https://doi.org/10.4236/ojemd.2018.81002

Received: November 29, 2017 Accepted: December 30, 2017 Published: January 2, 2018

Copyright $\odot 2018$ by authors and Scientific Research Publishing Inc. This work is licensed under the Creative Commons Attribution International License (CC BY 4.0).

http://creativecommons.org/licenses/by/4.0/

\begin{abstract}
Introduction: The objective of our study was to describe the socio-demographic characteristics and cardiovascular risk factors (RVFs) of diabetic patients admitted for stroke in a department other than neurology. Methods: Retrospective cross-sectional study over a period of six (6) years (January 2010 and December 2016), performed at the Internal Medicine Department of the Abass Ndao Hospital Center in Dakar. Results: 79 adults with a mean age of 64.67 years, a female predominance (51.89\%). The major risk factors found were arterial hypertension in $74.68 \%$ of cases, dyslipidemia in $32.35 \%$ of cases, smoking in $6.32 \%$ of cases. The reasons for consultation were a disorder of consciousness in $27.4 \%$ of cases, hemiplegia in $43.3 \%$ of cases, headache in $18.98 \%$ of cases, vertigo in $8.86 \%$ and dysarthria in $10.12 \%$ of the cases. Mean systolic blood pressure was $150 \mathrm{mmHg}$, mean diastolic blood pressure was $86 \mathrm{mmHg}$. The average blood glucose was $3 \mathrm{~g} / \mathrm{l}$. Strokes were associated with left ventricular hypertrophy in $30.55 \%$ of cases. Ischemic stroke accounted for $74.68 \%$. The evolution was marked by a death in $20.25 \%$ (16) cases. Conclusion: Stroke is a major public health problem. Despite its predominance of women, they (stroke) affected $48.10 \%$ of men in our study when we know that in Africa the social activity is based on men. They remain a serious pathology in the diabetic by the high lethality.
\end{abstract}

\section{Keywords}

Africa, Chronic Complications, Diabetes, Mortality 


\section{Introduction}

Diabetes is a public health problem because of the medical, social, and financial implications [1]. The International Diabetes Federation (IDF) 2015 estimates report a prevalence of $8.8 \%$. Prevalence in sub-Saharan Africa will increase from $4.8 \%$ to $5.7 \%$ [2]. In Senegal, prevalence data remain approximate. According to 2015 IDF estimates, 3.4\% of the Senegalese population is diabetic [2]. Diabetes is a leading cause of blindness, kidney failure, heart attack, stroke and lower limb amputation [3]. Stroke (all-cause) is the second leading cause of death in the world [4] [5], and recent studies show that mortality rates for ischemic stroke or cerebral hemorrhage are much higher in developing countries than in the industrialized countries [6] [7]. Nevertheless prospective data in diabetics are rare on the management and the short and medium term evolution of these pathologies in sub-Saharan Africa [8] [9]. The objective of our study was to describe the socio-demographic characteristics and Cardiovascular Risk Factors for diabetic patients admitted to stroke in an internal medicine unit to help better identify prevention targets.

\section{Material and Methods}

This was a descriptive retrospective study from January 2010 to December $31^{\text {st }}$ of 2016, performed in the internal medicine department of the Abass Ndao hospital center. It concerned diabetic patients of all ages admitted during the period of study for neurovascular accident documented by a systematic brain scan. Stroke was excluded from the study and not documented by cerebral computed tomography (CT) scans. The diagnosis of the stroke was clinical and paraclinical: Clinic: any patient presenting with neurological clinical abnormality lasting more than 24 hours; paraclinical: based on scan criteria. Non-hospitalized diabetic subjects, patients transferred or abused or with undocumented stroke were excluded. For this survey, we selected the following variables:

- Sociodemographic characteristics: sex, age grouped by slice and occupation, provenance;

- Study of diabetes mellitus: seniority, type of diabetes, nature of treatment, associated cardiovascular risk factors, level of glycemic equilibrium using fasting glucose and treatment of patients;

- A review of cardiovascular risk factors.

Those considered in this study, since all patients are diabetic, were: age ( $>55$ years in men and 60 years in women), active smoking, sedentary lifestyle, blood pressure over $130 \mathrm{mmHg}$, obesity, dyslipidemia, micro albuminuria greater than $30 \mathrm{mg} / 24 \mathrm{~h}$, hypercholesterolemia $>2 \mathrm{~g} / \mathrm{l}$, hypoHDLemia $<0.35 \mathrm{~g} / \mathrm{l}$, hypertriglyceridemia. The lipid balance was performed during a checkup.

- The treatment: low sodium diet, drug treatment of diabetes and treatment of high blood pressure, platelet and antiplatelet therapy statins;

- Reasons for hospitalization: reasons mentioned in the medical file or in the reference bulletin for hospitalization;

- The study of pathologies associated with diabetes. 
Paraclinical data: fasting blood glucose; serum creatinine; the lipid balance the hemogram. CRP, computed tomography.

- The hospital outcome: we examined patient records to assess three possible outcomes: discharge from hospital, transfer to another department and finally death during hospitalization.

For the collection of data, we used the patient's medical record as well as the data that existed in the patient's hospital registry.

The capture and exploitation were carried out by SPSS STATISTICS 18.0 software.

\section{Results}

Clinic: 79 patients met the criteria for inclusion. The sample consisted of 41 women (51.89\%) and 38 men (48.10\%) with a sex ratio of 0.92 . The average age was 64.67 years with extremes [36 - 95 years]. Diabetes evolved for less than 5 years in 23.28\% of patients and inaugural in $14.28 \%$. All our patients had type 2 diabetes. The treatment was essentially insulin in $27.50 \%$ and oral anti-diabetics in $52.50 \%$. Mean fasting blood glucose was $3.5 \mathrm{mg} / \mathrm{dl}$ with extremes of 0.25 and HI. 62.67 patients had blood glucose ( $>2 \mathrm{mg} / \mathrm{dl}$ ). The Table 1 shows the partition of patients according to socio demographic characteristics.

Major risk factors were dominated by high blood pressure followed by dyslipidemia and tobacco $74.68 \%$ respectively; $32.35 \%$ and $6.32 \%$. The reasons for consultation were mainly loss of consciousness in $27.84 \%$ of cases, hemiplegia in $43.03 \%$ of cases, headache in $18.98 \%$ of cases, vertigo in $8.86 \%$ and dysarthria in $10.12 \%$ of the cases. On clinical examination they all had motor deficits, average systolic blood pressure was $147 \mathrm{mmHg}(60$ - 240), average diastolic blood pressure was $86 \mathrm{mmHg}(40$ - 140). The Table 2 shows the partition of patients according to clinical characteristic.

Para clinical: the electrocardiogram revealed a disturbance of the heart rhythm in $27.7 \%$ of cases, left atrial hypertrophy in $22.2 \%$ of cases and left ventricular hypertrophy in $30.55 \%$ of cases. Ischemic stroke was the dominant lesion type with $74.68 \%$ ischemic brain scan lesion and $12.65 \%$ normal CT scan and bleeding stroke $12.65 \%$ of cases. Immediate evolution: patients who had hemorrhagic stroke were all transferred to an intensive care unit and some ischemic stroke (15.18\%). The evolution was marked by a death in $20.25 \%$ (16) cases. The Table 3 shows the distribution of patients according to paraclinical characteristics.

\section{Discussion}

This retrospective study carried out at the internal medicine department of the Abass Ndao Dakar hospital, showed us an average age of patients admitted for stroke at 62.14 years. This average age is close to that of a predominantly black American population [8] with 62 years old. Other Africans [10] [11] [12] describe an average age ranging from 44.5 years to 61 years. In the African literature, there is a variability in prevalence by sex, either female or male: the majority of 
Table 1. Partition of patients according to socio demographic characteristics.

\begin{tabular}{|c|c|c|}
\hline Patients' characteristics & Number & Frequency $\%$ \\
\hline \multicolumn{3}{|l|}{ Sex } \\
\hline Masculine & 38 & 48.10 \\
\hline Feminine & 41 & 51.89 \\
\hline \multicolumn{3}{|l|}{ Age } \\
\hline Average & 64.67 & \\
\hline Extremes & {$[36-95]$} & \\
\hline$<40$ years & 1 & 1.26 \\
\hline [40 - 59] & 21 & 26.58 \\
\hline$>60$ years & 57 & 72.15 \\
\hline Address & 72 & \\
\hline Dakar & 68 & 86.07 \\
\hline Out of Dakar & 4 & 5.55 \\
\hline Profession & 46 & \\
\hline Retreated & 13 & 28.26 \\
\hline Housewives & 19 & 41.3 \\
\hline without & 9 & 19.56 \\
\hline Others & 5 & 10.86 \\
\hline Diabetes duration & 63 & \\
\hline Inaugural & 9 & 14.28 \\
\hline$<5$ years & 15 & 23.28 \\
\hline [5 - 9 years] & 8 & 12.69 \\
\hline$>10$ years & 31 & 49.20 \\
\hline Diabetes treatment & 40 & \\
\hline Diet alone & 7 & 17.50 \\
\hline $\mathrm{OAD}$ & 21 & 52.50 \\
\hline Insuline & 11 & 27.50 \\
\hline \multicolumn{3}{|l|}{ Stemming } \\
\hline Exeat & 51 & 64.55 \\
\hline Transfered & 12 & 15.18 \\
\hline deceased & 16 & 20.25 \\
\hline
\end{tabular}

studies favored a male preponderance with a ratio between 1.3 and 1.5 [13] [14] [15]. Ratios to 2 have been described [10], as well as a female preponderance with ratios between 0.82 and 0.97 [16] [17]. The predominance was female in our study with a sex ratio of 0.92 . In Ivory Coast a Masculine predominance has already been described [18].

The major risk factors were dominated by arterial hypertension followed by diabetes and tobacco respectively $74.68 \% ; 32.35 \%$ and $6.32 \%$. Hypertension as the 
Table 2. Partition of patients according to clinical characteristic.

\begin{tabular}{|c|c|c|}
\hline Clinical characteristics & Number & Frequency $\%$ \\
\hline \multicolumn{3}{|l|}{ Clinical signs } \\
\hline Headaches & 15 & 18.98 \\
\hline Disorders of consciousness & 22 & 27.84 \\
\hline Dizziness & 7 & 8.86 \\
\hline Hemiplegia & 34 & 43.03 \\
\hline Hemiparesis & 11 & 13.92 \\
\hline Aphasia & 16 & 20.25 \\
\hline dysarthria & 8 & 10.12 \\
\hline Paraplegia & 1 & 1.26 \\
\hline Monoplegia & 3 & 3.79 \\
\hline Balance disorder & 2 & 2.53 \\
\hline Peripheral facial paralysis & 4 & 5.06 \\
\hline Polyuria & 21 & 26.58 \\
\hline Polydipsia & 19 & 24.05 \\
\hline Fall & 2 & 2.53 \\
\hline Ptosis & 1 & 1.26 \\
\hline Amnesia & 1 & 1.26 \\
\hline Constipation & 1 & 1.26 \\
\hline vomiting & 13 & 16.45 \\
\hline \multicolumn{3}{|l|}{ RISK FACTOR } \\
\hline HTA & 59 & 74.68 \\
\hline Tabac & 5 & 6.32 \\
\hline Alcohol & 3 & 3.79 \\
\hline \multicolumn{3}{|l|}{ Antecedents } \\
\hline Hypertension & 4 & 5.06 \\
\hline Amputation & 4 & 5.06 \\
\hline Thrombophlebitis & 2 & 2.53 \\
\hline Glycemia & 67 & \\
\hline Average & 3.5 & \\
\hline Extremes & 025-HI & \\
\hline$>2 \mathrm{mg} / \mathrm{dl}$ & 42 & 62.67 \\
\hline $\mathrm{HI}$ & 3 & 4.47 \\
\hline Systolic blood pressure & 75 & \\
\hline Average & 14.93 & \\
\hline Extremes & $6-24$ & \\
\hline$>140 \mathrm{mmHg}$ & 49 & 65.33 \\
\hline Distolic Blood Pressure & 75 & \\
\hline Average & 865 & \\
\hline Extremes & {$[4-14]$} & \\
\hline$>10 \mathrm{mmHg}$ & 22 & 29.33 \\
\hline
\end{tabular}


Table 3. Distribution of patients according to paraclinical characteristics.

\begin{tabular}{|c|c|c|}
\hline Paraclinical data & Number & Frequency \% \\
\hline ECG & 36 & \\
\hline Normal & 10 & 27.7 \\
\hline HVG & 11 & 30.55 \\
\hline HAG & 8 & 22.2 \\
\hline Rhythm disorder & 10 & 27.7 \\
\hline Branch block & 4 & 11.11 \\
\hline Ischemia-lesion & 5 & 13.88 \\
\hline Doppler ultrasound & 18 & \\
\hline par & 7 & 38.88 \\
\hline abnormal & 11 & 61.11 \\
\hline HVG & 5 & 27.77 \\
\hline \multicolumn{3}{|l|}{ Computed tomography } \\
\hline Sylvian artery & 28 & 35.44 \\
\hline ACA & 10 & 12.65 \\
\hline $\mathrm{ACP}$ & 5 & 6.32 \\
\hline Jonctionnelle & 2 & 2.53 \\
\hline \multicolumn{3}{|l|}{ Type d'AVC } \\
\hline AIT & 10 & 12.65 \\
\hline AVCI & 59 & 74.68 \\
\hline $\mathrm{AVCH}$ & 10 & 12.65 \\
\hline Ultrasound of supra aortic trunks & 6 & \\
\hline Normal & 3 & 50 \\
\hline Abnormal & 3 & 50 \\
\hline Complete blood count & 53 & \\
\hline Anemia & 15 & 28.30 \\
\hline Leukocytosis & 24 & 45.28 \\
\hline CRP & 29 & \\
\hline Average & 102.3 & \\
\hline Negative & 4 & 13.80 \\
\hline Positive & 25 & 86.20 \\
\hline HBA1C & 12 & \\
\hline Average & 8 & \\
\hline$>7 \%$ & 7 & 58.3 \\
\hline Creatinine & 50 & \\
\hline Average & 17.37 & \\
\hline$>13 \mathrm{mg} / \mathrm{l}$ & 13 & 26 \\
\hline Bilan lipidique & 34 & \\
\hline Total cholesterol $>2 \mathrm{~g} / \mathrm{l}$ & 11 & 32.35 \\
\hline Hypo HDL & 9 & 26.47 \\
\hline $\mathrm{LDL}>1 \mathrm{~g} / \mathrm{l}$ & 22 & 64.70 \\
\hline Hypertriglyceridemia & 2 & 5.88 \\
\hline
\end{tabular}


main risk factor is described everywhere, both in Africa [10] [11] and in developed countries [19]. The frequency of risk factors would be different in black subjects with successively hypertension, smoking, diabetes, heart disease while in Caucasian subjects it would be smoking, hypertension, heart disease, alcoholism, diabetes [19].

For dyslipidemia, several major epidemiological studies have highlighted the link between lipid abnormalities and cardiovascular risk in type 2 diabetics. Thus, in the UKPDS [20] and the Strong Heart Study [21], cardiovascular risk is multivariate analysis, positively associated with LDL-cholesterol and negatively with HDL-cholesterol levels.

The reasons for consultation found (loss of consciousness, hemiplegia, headaches) in our study have already been written in the literature [22] [23]. In one large European cohort study has shown that diabetic subjects had more motor deficit and dysarthria, while aphasia and swallowing disorders were more common in non-diabetics [24].

In our study diabetes was unbalanced in $58 \%$ of patients. The elevation of glycated hemoglobin ( $\mathrm{Hb} \mathrm{AlC}$ ) would also be correlated with a pejorative prognosis. In the UKPDS study, A1C elevation of $1 \%$ was associated with a $37 \%$ increase in stroke lethality [25]. Hyperglycemia is frequently observed in the acute phase of stroke and is life-threatening, exacerbating the risk of early death.

The deleterious mechanisms of hyperglycemia would include pro-coagulant action and decreased fibrinolysis, reduced reperfusion of ischemic tissue, and increased size of necrosis. Hyperglycemia increases reperfusion-related lesions, accounting for the greater frequency of hemorrhagic changes [26] [27]. In the search for emboligenic heart disease we found a heart rhythm disorder in 27.7\% of cases. Coulibally et al. [11] in Mali and Bendriss et al. [28] in Morocco reported proportions of $19.7 \%$ and $17.3 \%$ respectively, while for Lazzaro et al. [29] it was slightly lower (6\%). These differences are related to the mode of selection of the patients, the type, and especially the duration of recording. Thus a recording over a longer period ( 48 or 72 hours) makes it possible to significantly increase the probability of detection of atrial fibrillation [30]. Our lethality (25\%) is concordant with that observed (10\% to $60 \%)$ in the African literature [31]. This is due to the late management of patients in hospital structures. This rate is higher than in the West where rapid admission to the neurovascular unit reduces stroke mortality [32]. The limits of the study are constituted by the fact that it is about a study on file of patients. The collection of data was not exhaustive clinically and paraclinically. Microalbuminuria, arterial echo doppler in search of arterial disease and effective diabetic nephropathy and fundus were not performed in all patients because of the high cost of these central examinations.

\section{Conclusion}

Diabetes is a major risk factor for stroke. Hence, hyperglycemia should be treated early and effectively in the acute phase of stroke and all vascular risk factors associated with diabetes, including hypertension. 


\section{References}

[1] Diop, S.N. (2015) Diabetes Mellitus in Sub-Saharan Africa: Epidemiological and Socioeconomic Aspects. Medicine of Metabolic Diseases, 9, 123-129.

[2] International Diabetes Federation (IDF) (2017) IDF Diabetes Atlas. 8th Edition, International Diabetes Federation, Brussels. http://www.diabetesatlas.org/resources/2017-atlas.html

[3] WHO (2016) World Diabetes Report. World Health Organization, Geneva.

[4] World Health Organization (2002) The World Health Report 2002: Reducing Risks, Promoting Healthy Life. World Health Organization, Geneva.

[5] Feigin, V.L., Lawes, C.M., Bennett, D.A. and Anderson, C.S. (2003) Stroke Epidemiology: A Review of Population-Based Studies of Incidence, Prevalence, and Case-Fatality in the Late 20th Century. The Lancet Neurology, 2, 43-53. https://doi.org/10.1016/S1474-4422(03)00266-7

[6] Connor, M.D., Walker, R., Modi, G. and Warlow, C.P. (2007) Burden of Stroke in Black Populations in Sub-Saharan Africa. The Lancet Neurology, 6, 269-278. https://doi.org/10.1016/S1474-4422(07)70002-9

[7] Lemogoum, D., Degaute, J.P. and Bovet, P. (2005) Stroke Prevention, Treatment, and Rehabilitation in Sub-Saharan Africa. American Journal of Preventive Medicine, 29, 95-101. https://doi.org/10.1016/j.amepre.2005.07.025

[8] Séne Diouf, F., Mapoure, N.Y., Ndiaye, M., Mbatchou Ngahane, H.B., Toure, K., Thiam, A., et al. (2008) Survival of Comatose Stroke in Dakar, Senegal. Revista De Neurologia, 164, 452-458.

[9] Sokrab, T.E., Sid-Ahmed, F.M. and Idris, M.N. (2002) Acute Stroke Type, Risk Factors, and Early Outcome in a Developing Country: A View from Sudan Using a Hospital-Based Sample. Journal of Stroke \& Cerebrovascular Diseases, 11, 63-65. https://doi.org/10.1053/jscd.2002.126690

[10] Sagui, E. (2007) Stroke in Sub-Saharan Africa. Medecine Tropicale, 67, 596-600.

[11] Coulibaly, S., Diakite, S., Diall, I.B., Menta, I., Sacko, A.K. and Diallo, B. (2010) Stroke: Risk Factors, Evolution and Prognosis in the Cardiac Department "B" of the Point CHU G, Bamako. Mali Medical, 25, 32-36.

[12] Diagana, M., Traore, H., Bassima, A., Druet-Cabanac, M., Preux, P.M. and Dumas, M. (2002) Contribution of Computerized Tomography in the Diagnosis of Cerebral Vascular Accidents in Nouakchott, Mauritania. Medecine Tropicale, 62, 145-149.

[13] Keita, A.D., Toure, M., Diawara, A., et al. (2005) Epidemiological Aspects of Cerebrovascular Accidents in the Computed Tomography Department at the G-Point Hospital in Bamako. Mali Medical, 65, 453-457.

[14] Sene, D.F., Lower, A.M., Ndao, A.K., Ndiaye, M., et al. (2006) Functional Prognosis of Cerebrovascular Accidents in Developing Countries: Senegal. Annales De Readaptation Et De Medecine Physique, 49, 100-104.

[15] Zenebe, G., Alemayehu, M. and Asmera, J. (2005) Characteristics and Outcomes of Stroke at Tikur Anbessa Teaching Hospital, Ethiopia. Ethiopian Medical Journal, 43, 251-259.

[16] Garbusinski, J.M., van der Sande, M.A., Bartholomew, E.J., Dramaix, M., Gaye, A., Coleman, R., Nyan, O.A., Walker, R.W., McAdam, K.P. and Walraven, G.E. (2005) Stroke Presentation and Outcome in Developing Countries: A Prospective Study in the Gambia. Stroke, 36, 1388-1393.

https://doi.org/10.1161/01.STR.0000170717.91591.7d 
[17] Ogun, S.A., Ojini, F.I., Ogungbo, B., Kolapo, K.O. and Danesi, M.A. (2005) Stroke in South West Nigeria: A 10-Year Review. Stroke, 36, 1120-1122. https://doi.org/10.1161/01.STR.0000166182.50840.31

[18] Cowppli-bony, P., Sonan-Douayoua, T., Akani, F., Ahogo, C., N'guessan, K. and Beugre, E.K. (2007) Epidemiology of Stroke in the Service of Bouake Neurology. Medicine of Black Africa, 54, 199-202.

[19] Hajat, C., Dundas, R., Stewart, J.A., Lawrence, E., Rudd, A.G., Howard, R. and Wolfe, C.D. (2001) Cerebrovascular Risk Factors and Stroke Subtypes, Differences between Ethnic Groups. Stroke, 32, 37-42. https://doi.org/10.1161/01.STR.32.1.37

[20] Turner, R.C., Millns, H., Neil, H.A., et al. (1998) Risk Factors for Coronary Artery Disease in Non-Insulin-Dependent Diabetes Mellitus: United Kingdom Prospective Diabetes Study (UKPDS: 23). BMJ, 14, 823-828.

[21] Howard, B.V., Robbins, D.C., Sievers, M.L., et al. (2000) LDL Cholesterol as a Strong Predictor of Coronary Heart Disease in Diabetic Patients with Insulin Resistance LDL: The Strong Heart Study. Arteriosclerosis, Thrombosis, and Vascular Biology, 20, 830-835. https://doi.org/10.1161/01.ATV.20.3.830

[22] Damorou, F., Togbossi, E., Pessinaba, S., Klouvi, Y., Balogou, A., Belo, M. and Soussou, B. (2008) Stroke and Emboligenic Cardio-Vascular Diseases. Le Mali Medical, 23, 33 .

[23] Cowppli-Bony, P., Yapi-Yapo, P., Douayoua-Sonan, T., Kouamé, B., Yapo, F.B. and Kouassi, E.B. (2006) Mortality Due to Cerebral Stroke. Medicine of Black Africa, 53, 299-305.

[24] Megherbi, S.E., Milan, C., Minier, D., Cover, G., Osseby, G.V., Tilling, K., Di Carlo, A., et al. (2003) Association of Diabetes and Stress Subtype on Survival and Functional Outcome 3 Months after Stroke: Data from the European BIOMED Stroke Project. Stroke, 34, 688-694. https://doi.org/10.1161/01.STR.0000057975.15221.40

[25] Stevens, R.J., Coleman, R.L., Adler, A.I., Stratton, I.M., Matthews, D.R. and Holman, R.R. (2004) Risk Factors for Myocardial Infarction Case Fatality and Stroke Case Fatality in Type 2 Diabetes: UKPDS 66. Diabetes Care, 27, 201-207. https://doi.org/10.2337/diacare.27.1.201

[26] Kruyt, N.D., Biessels, G.J., Devries, J.H. and Roos, Y.B. (2010) Hyperglycemia in Acute Ischemic Stroke: Pathophysiology and Clinical Management. Nature Reviews Neurology, 6, 145-155. https://doi.org/10.1038/nrneurol.2009.231

[27] Haratz, S. and Tanne, D. (2011) Diabetes, Hyperglycemia and the Management of Cerebrovascular Disease. Current Opinion in Neurology, 24, 81-88. https://doi.org/10.1097/WCO.0b013e3283418fed

[28] Bendriss, L. and Khatouri, A. (2012) Ischemic Strokes. Frequency of Cardiovascular Etiologies Documented by Extensive Cardiovascular Assessment. About 110 Cases. Annales De Cardiologie Et D'Angeiologie (Paris), 61, 252-256. https://doi.org/10.1016/j.ancard.2012.04.011

[29] Lazzaro, M.A., Krishnan, K. and Prabhakaran, S. (2012) Detection of Atrial Fibrillation with Concurrent Holter Monitoring and Continuous Cardiac Telemetry Following Ischemic Stroke and Transient Ischemic Attack. Journal of Stroke and Cerebrovascular Diseases, 21, 89-93. https://doi.org/10.1016/j.jstrokecerebrovasdis.2010.05.006

[30] Harris, K., Edwards, D. and Mant, J. (2012) How Can We Best Detect Atrial Fibrillation? The Journal of the Royal College of Physicians of Edinburgh, 42, 5-22.

[31] Toure, K., Kane, M., Kane, A., Tal/Dia, A., Ndiaye, M.M. and Ndiaye, I.P. (2010) Contribution of Computed Tomography in the Epidemiology of Cerebrovascular 
Accidents to the Grand Yoff General Hospital. Medicine of Black Africa, 57, 455-460.

[32] Sulter, G., Elting, J.W., Langedijk, M., et al. (2003) Admitting Acute Ischemic Stroke Patients to Stroke Monitoring Unit versus a Conventional Stroke Unit. Stroke, 34, 101-104. https://doi.org/10.1161/01.STR.0000048148.09143.6C 